\title{
Mass in the ear canal
}

\section{S Ghosh, S K Singhal, Y V Ramana}

Answers on $\mathrm{p} 301$.

\begin{abstract}
A 70 year old woman presented to outpatient department with a history of gradually progressive hearing loss in the right ear of one year's duration. There was no history of ear discharge, pain, tinnitus, or vertigo. Examination revealed a firm, skin lined mass that was not tender and was confined to the ear canal. Facial nerve functions were intact. The patient was advised to come for a biopsy after routine investigations (radiography of her mastoids and chest and haematology), but she missed follow up. Eight months later she presented to the outpatient department again with the same auricular mass, which had increased in size and was protruding out of the ear canal as shown in the fig 1 . Biopsy was performed, the mass was fleshy and moderately vascular and friable; microscopy findings are shown in the fig 2 .
\end{abstract}

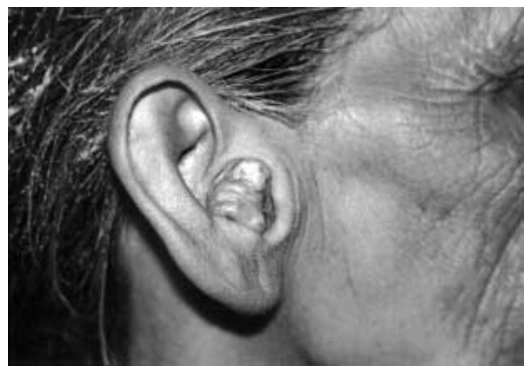

Figure 1 Skin covered mass in the right external auditory canal.

\section{QUESTIONS}

(1) What is the diagnosis?

(2) What further investigation is required?

(3) What are the peculiarities of this tumour?

(4) What is the treatment?

Postgrad Med J 2003;79:300

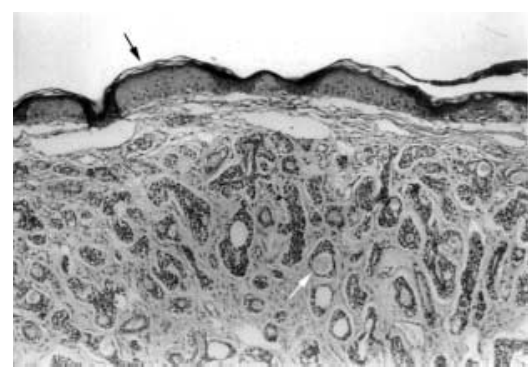

Figure 2 Microphotograph showing squamous lining of ear canal (arrowhead). Tumour is composed of tubular structures and cribriform pattern of cell rests (double arrowhead). Cells have rounded nuclei and scanty cytoplasm (haematoxylin and eosin $x$ 550.)

\section{Authors' affiliations}

S Ghosh, Department of Ear, Nose, and Throat, PGIMER and Government Medical College, Chandigarh, India

S K Singhal, Y V Ramana, Government

Medical College, Chandigarh, India

Correspondence to: Dr Shakuntala Ghosh, Department of Ear, Nose and Throat, PGIMER, Chandigarh, India; venkatdoc@hotmail.com

Submitted 12 July 2002

Accepted 8 October 2002

\section{QUESTIONS}

(1) What is the likely diagnosis?

(2) Which test should be recommended to confirm the diagnosis?

(3) What treatment should be offered for the pulmonary embolism?

Postgrad Med J 2003;79:300

\section{Authors' affiliations}

S G Williams, P Currie, Department of Cardiology, Arrowe Park Hospital, Wirral, UK D W Galvani, Department of Haematology

a deep vein thrombosis. A clinical diagnosis of pulmonary embolism was made and before starting the patient on low molecular weight heparin for treatment, a full blood count was performed. This revealed a haemoglobin concentration of $134 \mathrm{~g} / \mathrm{l}$, white cell count $7.6 \times 10^{\circ} / \mathrm{l}$, and platelets $17 \times 10^{9} / 1$.
Correspondence to: Dr Simon G Williams, Department of Cardiology, Arrowe Park Hospital, Arrowe Park Road, Upton, Wirral CH49 5PE, UK; drsgwilliams@hotmail.com

Submitted 12 December 2002

Accepted 20 December 2002 